\title{
Rb regulates proliferation and rod photoreceptor development in the mouse retina
}

\author{
Jiakun Zhang ${ }^{1}$, Jonathan Gray ${ }^{1}$, Lizhao $\mathrm{Wu}^{2}$, Gustavo Leone ${ }^{2}$, Sheldon Rowan ${ }^{3}$, Constance L Cepko ${ }^{3}$, \\ Xuemei Zhu ${ }^{4}$, Cheryl M Craft ${ }^{4} \&$ Michael A Dyer ${ }^{1}$
}

\begin{abstract}
The retinoblastoma protein $(\mathbf{R b})$ regulates proliferation, cell fate specification and differentiation in the developing central nervous system (CNS), but the role of $\mathbf{R b}$ in the developing mouse retina has not been studied, because $\mathbf{R b}$-deficient embryos die before the retinas are fully formed. We combined several genetic approaches to explore the role of Rb in the mouse retina. During postnatal development, $\mathrm{Rb}$ is expressed in proliferating retinal progenitor cells and differentiating rod photoreceptors. In the absence of $\mathbf{R b}$, progenitor cells continue to divide, and rods do not mature. To determine whether Rb functions in these processes in a cell-autonomous manner, we used a replication-incompetent retrovirus encoding Cre recombinase to inactivate the $R b 1^{l o x}$ allele in individual retinal progenitor cells in vivo. Combined with data from studies of conditional inactivation of $R \boldsymbol{b} 1$ using a combination of Cre transgenic mouse lines, these results show that $\mathbf{R b}$ is required in a cell-autonomous manner for appropriate exit from the cell cycle of retinal progenitor cells and for rod development.
\end{abstract}

In the mouse, the seven main classes of retinal cell types (rod, cone, bipolar, horizontal, amacrine, ganglion and Müller glial cells) are produced from multipotent progenitor cells over a 17-d interval starting at embryonic day (E) 11.5 and continuing through postnatal day (P) 9. The overall size of the retina and the proportion of each cell type contained therein is essential for proper visual processing; therefore, during retinal development, cell cycle exit and cell fate specification are coordinated to ensure that the adult retina forms appropriately ${ }^{1,2}$. When cell proliferation and cell fate specification become uncoupled, as in retinoblastoma ${ }^{3}$, microphthalmia ${ }^{4,5}$ and some forms of retinal dysplasia ${ }^{6,7}$ and degeneration ${ }^{8}$, vision is severely compromised. By studying individual proteins that integrate the decision to exit the cell cycle and to specify cell fate, we may begin to gain insights into the synchronization of these two important processes during neural development.

$\mathrm{Rb}$ lies at the heart of the regulatory network that executes cell cycle exit during the G1 phase through interactions with the E2F transcription factor family. There is also evidence that $\mathrm{Rb}$ has a role in cell fate specification $^{9-11}$. In support of this notion, Rb can bind more than 110 different proteins, several of which are tissue-restricted transcription factors $^{12}$. It is conceivable that $\mathrm{Rb}$ binds to $\mathrm{E} 2 \mathrm{~F}$ and regulates cell cycle exit through its canonical pathway and then contributes to cell fate specification, differentiation or both through interactions with tissuerestricted transcription factors.

To overcome the embryonic lethality of $\mathrm{Rb}^{-/-}$embryos, which die in utero around E13.5, we used an explant culture procedure to study the development of isolated whole retinas beyond E13.5. To complement and extend the explant culture studies in vivo, we inactivated the gene $R b 1$ in the retina by using a new tissue-specific Cre transgenic line (Chx10-cre) crossed to $R b 1^{\text {lox }}$ mice. Finally, we injected a Cre-expressing replication-incompetent retrovirus into the eyes of newborn $R b 1^{\text {lox }}$ mice to generate clones of cells lacking $\mathrm{Rb}$. These experiments showed that $\mathrm{Rb}$ is required in a cell-autonomous manner for appropriate cell cycle exit and rod development in the mouse retina. This is the first example of a cell-autonomous role for an Rb family member in these two interrelated processes in the developing retina.

\section{RESULTS}

$\mathbf{R b}$ expression during development

To identify the cells expressing $\mathrm{Rb}$ in the developing mouse retina, we immunolabeled retinal cryosections at six postnatal stages of development (P0, P3, P6, P9, P12 and P21). At P0, when approximately $35 \%$ of cells are still dividing and $65 \%$ are postmitotic ${ }^{1,13}$ (R. Martins and M.A.D., unpublished results), $\mathrm{Rb}$ was expressed in the nuclei of dividing retinal progenitor cells in the outer neuroblastic layer and postmitotic differentiating neurons in the developing inner nuclear layer (Fig. 1a-d). To verify that the cells expressing $\mathrm{Rb}$ in the outer neuroblastic layer were actively dividing, we labeled retinas of $\mathrm{P} 0$ embryos with $\mathrm{H}^{3}$ thymidine for $1 \mathrm{~h}$, dissociated the cells, plated them on glass slides and immunolabeled them with an antibody to Rb. We identified the cells in $S$ phase at the time of labeling by autoradiography (Fig. 1e-h). We scored approximately 5,000 cells during three separate experiments and

${ }^{1}$ Department of Developmental Neurobiology, St. Jude Children's Research Hospital, Memphis, Tennessee 38105, USA. ${ }^{2}$ Department of Molecular Genetics, Ohio State University, Columbus, Ohio 43210, USA. ${ }^{3}$ Department of Genetics and Howard Hughes Medical Institute, Harvard Medical School, Boston, Massachusetts 02115, USA. ${ }^{4}$ Department of Cell and Neurobiology, University of Southern California, Los Angeles, California 90033, USA. Correspondence should be addressed to M.A.D. (michael.dyer@stjude.org). 
Figure 1 Temporal expression and distribution of $\mathrm{Rb}$ in mouse retinas during development. (a) Proliferating retinal progenitor cells are located in the outer neuroblastic layer in the newborn mouse (PO) retina. Postmitotic neurons accumulate along the apical and basal surfaces and ultimately form the laminar structure of the mature retina. (b-d) $\mathrm{Rb}$ (green) was expressed in the nuclei (red) of PO mouse retinal progenitor cells and postmitotic cells in the inner neuroblastic layer (open arrowhead) and developing ganglion cell layer and developing outer nuclear layer (arrow). (e-h) Immunofluorescence and autoradiographic analyses of individual retinal cells from PO mice showed that Rb (red) was localized in the nuclei (blue) of cells that were ${ }^{3} \mathrm{H}$-thymidine-positive (arrow). (i-I) In retinas of P14 mice, Rb (green) was expressed in the nuclei (red) of photoreceptors in the outer nuclear layer and in neurons and glia in the inner nuclear layer and ganglion cell layer. Rb had a distinct nuclear staining pattern (arrow) in photoreceptors compared with that seen in other neurons (open arrowhead). $\mathrm{ONBL}$, outer neuroblastic layer; INBL, inner neuroblastic layer; ONL, outer nuclear layer; INL, inner nuclear layer; OPL, outer plexiform layer. Scale bars: b,c,i,j, $25 \mu \mathrm{m} ; \mathbf{d}, \mathbf{e}, \mathbf{k}, \mathbf{l}, 10 \mu \mathrm{m}$.
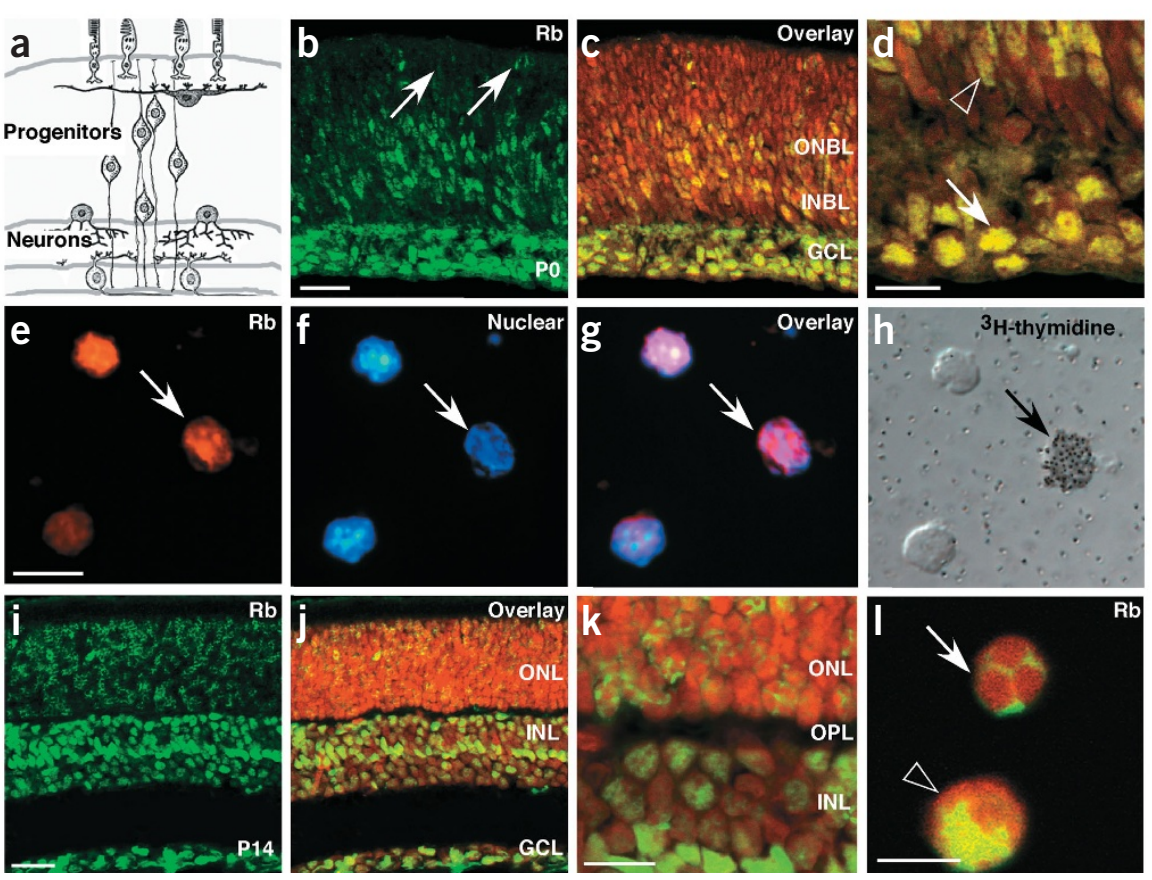

found that $85 \pm 6 \%$ of the $\mathrm{H}^{3}$-thymidine-positive cells were also $\mathrm{Rb}$ immunopositive. We also found that $20.3 \pm 1.2 \%$ of Rb-immunopositive cells were ${ }^{3} \mathrm{H}$-thymidine positive. The pattern of $\mathrm{Rb}$ expression was similar at P3 (data not shown). At later postnatal stages, Rb was expressed in the nuclei of postmitotic neurons and Müller glia in the inner nuclear layer (Fig. 1i,j). Rb was also found in the rod photoreceptor cells in the retinas of embryos at P12-P21 in a characteristic cagelike distribution circumscribing heterochromatin ${ }^{14}$ (Fig. 1k). The subcellular localization of $\mathrm{Rb}$ in rod photoreceptors was preserved in dissociated cells of the postnatal retina (Fig. 11).

\section{Rb-deficient retinas contain extra cells}

$\mathrm{Rb}^{-1-}$ embryos die at E13.5 with hematopoietic and CNS defects ${ }^{15-17}$. To test whether $\mathrm{Rb}$ is required for cell cycle exit, cell fate specification, differentiation or all of these processes in the developing mouse retina, we maintained retinas from E13.5 $R b 1^{-/-}, R b 1^{+/-}$and $R b 1^{+/+}$embryos in culture for $12 \mathrm{~d}$ (Fig. 2a). Retinas from Rb-deficient embryos were larger than those from $\mathrm{Rb}^{+/+}$embryos after $12 \mathrm{~d}$ in culture (Fig. 2b), and scoring of dissociated cells showed that the retinas of $\mathrm{RbI}^{-1}$ embryos contained more cells $\left(2.86 \times 10^{6} \pm 0.37 \times 10^{6}\right)$ than did those of $R b 1^{+/-}$embryos $\left(1.7 \times 10^{6} \pm 0.27 \times 10^{6}\right)$ or $R b 1^{+/+}$embryos $(1.61 \times$ $\left.10^{6} \pm 0.25 \times 10^{6} ; P<0.001\right)$.

To determine when the ectopic cell division occurred, we labeled retinas from $\mathrm{Rb}^{-/-}, \mathrm{Rb}^{+/-}$and $\mathrm{Rb} 1^{+/+}$embryos with 5-bromodeoxyuridine (BrdU) at three different stages. We dissociated the retinas and found that the percentage of $\mathrm{BrdU}^{+}$cells at either E13.5 or after $2 \mathrm{~d}$ in culture (DIC; E13.5 + 2 DIC) were the same in retinas from Rb-deficient and wild-type embryos (Fig. 2c,d and data not shown). Similarly, cell cycle proteins such as p57 (also called Kip2), cyclin D1 and p27 (also called Kip1) were indistinguishable at these stages (data not shown). During the later culture period (E13.5 + 6 DIC), however, the percentage of $\mathrm{BrdU}^{+}$cells in the retinas of $\mathrm{Rb}^{-/-}$embryos (30.1 \pm $1.9 \%)$ was higher than in retinas of $R b 1^{+/-}(22.6 \pm 1.7 \%)$ or wild-type $(21.9 \pm 0.9 \% ; P<0.01)$ littermates.

A subset of $\mathrm{Rbl}^{-1-}$ neural progenitor cells inappropriately enter $\mathrm{S}$ phase and undergo apoptosis or G2 arrest ${ }^{18}$. To determine whether this was occurring in the developing retina, we examined the DNA content by fluorescence-activated cell sorting (FACS) analysis and carried out a TUNEL assay at three different stages. We did not detect a significant difference in the proportion of cells in G2 or apoptotic nuclei in the retinas from $R b 1^{-/-}, R b 1^{+/-}$or wild-type littermates (Fig. 2e-k and data not shown). In the lenses of E13.5 $R b 1^{-1-}$ embryos, however, there was ectopic S-phase entry as measured by BrdU incorporation (data not shown) accompanied by apoptosis (Fig. 2g,h).

\section{$\mathbf{R b}$-deficient retinas lack rod photoreceptors}

The laminar organization of retinas from $\mathrm{Rb}^{-1-}$ embryos was severely disrupted (Fig. 2k). To determine whether this disorganization was caused by alterations in retinal cell fate specification or differentiation, we immunolabeled cryosections (from embryos at E13.5 or E13.5 + 4, 8 or 12 DIC) with 36 antibodies (Supplementary Table 1 online) raised against classes or subtypes of retinal neurons or proteins found in neuronal synapses. Only markers for rod photoreceptors were substantially different in retinas of $\mathrm{Rbl}^{-/-}$embryos (Fig. 3a-h). The levels of rhodopsin, a late marker of rod differentiation, and recoverin, an earlier marker of photoreceptor differentiation, were lower in retinas of $R b 1^{-1-}$ embryos compared with wild-type embryos. Proteins associated with rod synapses, including SNAP-25 (ref. 19), Bassoon ${ }^{20}$, PSD-95 (ref. 21) and Kinesin II (ref. 22), were also less abundant in retinas from $\mathrm{Rb}^{-1-}$ embryos (data not shown). Immunostaining with antibodies against M-opsin, S-opsin and cone arrestin showed that cones developed normally in the retinas of Rb1-deficient embryos (Fig. 3i-1).

To accurately measure the percentage of each of the seven main classes of retinal cell types in $R b 1^{+/+}, R b 1^{+/-}$and $\mathrm{Rb}^{-/-}$explants, we dissociated the retinas and immunolabeled them with antibodies that recognize each cell type in the mouse retina. We scored individual immunopositive cells in five independent samples from each genotype (Fig. $3 \mathbf{m}-\mathbf{u}$ ). Only the proportion of rods was reduced in retinas of $\mathrm{Rb}^{-{ }^{-}}$embryos compared with heterozygous and wild-type embryos. Data obtained from retinal microarray hybridization (Tables 1 and 2) with RNA prepared from retinas of $R b 1^{+/+}, R b 1^{+/-}$and $R b 1^{-/-}$embryos cultured for $12 \mathrm{~d}$ were consistent with the immunolabeling data. Furthermore, the 
microarray data indicated that $\mathrm{Nrl}$ gene expression was lower in retinas of $\mathrm{Rb}^{-1-}$ embryos, suggesting that $\mathrm{Rb}$ acts upstream of $\mathrm{Nrl}$ in rod photoreceptor development. Real-time RT-PCR analysis of cDNA prepared from cultured retinas of $R b 1^{-/-}, R b 1^{+/-}$and $R b 1^{+/+}$embryos confirmed these results (Supplementary Fig. 1 online).

Restoration of $\mathrm{Rb}$ to the placenta of developing embryos partially rescued the embryonic lethality of Rb-deficient embryos ${ }^{23}$. Cre expression from the Mox 2 promoter leads to recombination in the E6.5 embryo with no recombination in extraembryonic endoderm or trophoblast. We isolated retinas from $R b 1^{\text {lox/- }}$ Mox2-cre embryos ${ }^{23}$ and their littermates at E18.5 and cultured them for $12 \mathrm{~d}$. We then sectioned or dissociated the retinal explants and immunostained them with cell type-specific antibodies (Supplementary Table 1 online). As with the retinal explants of E13.5 $\mathrm{Rbl}^{-/-}$embryos, all rod photoreceptor markers were markedly reduced in the retinas of $R b 1^{\text {lox/- }}$ Mox2-cre embryos but not in those of $R b 1^{\text {lox/+ }}$ Mox2-cre or $R b 1^{\text {lox/- }}$ embryos (Supplementary Fig. 2 and Supplementary Table 3 online).

To verify that the proliferation and rod development phenotypes seen in the $\mathrm{Rbl}^{-/-}$retinal explants also occurred in vivo, we characterized transgenic mice carrying Cre recombinase under the control of the Chx10 promoter (S.R. and C.L.C., unpublished data). Most, if not all, retinal progenitor cells express Chx10 during retinal development in the mouse $\mathrm{e}^{4,5}$. Using reporter genes for green fluorescent protein (GFP) and alkaline phosphatase in the BAC Chx10 transgenic construct, we characterized the expression of Cre from the transgene. In retinal progenitor cells from E11.5 through P3, the transgene was expressed in large clusters (50-500) of cells. In the adult retina, the transgene was expressed in most bipolar cells and a subset of Müller glia (J.Z. and M.A.D., unpublished results). To test for Cre-mediated recombination, we crossed the Chx10 transgenic line to a ROSA26R reporter mouse line and stained cells for $\beta$-galactosidase activity. The ROSA26R mouse contains a lac $Z$ transgene with a stop codon flanked by loxP sites. Cremediated recombination restores the open reading frame of lac $Z$. Adult retinas isolated from these mice and stained with $X$-gal had broad patches of cells that had undergone Cre-mediated recombination (J.Z. and M.A.D., unpublished results). Next, we analyzed the retinas from $R b 1^{\text {lox/- }}$ carrying the Chx10-cre transgene by immunostaining retinal sections with the 36 antibodies used to characterize the retinal explants. Like $R b 1^{-/-}$mice, the retinas of $R b 1^{\text {lox/- }}$ Chx10-cre mice lacked rod photoreceptors in broad patches, consistent with the expression of Cre (Fig. 4a-g and data not shown). There was no obvious change in the proportion or distribution of cone photoreceptors in these retinas, although the laminar organization was disrupted due to the loss of rods (Fig. $4 \mathbf{h}-\mathbf{k})$. In general, the outer plexiform layer was disrupted in retinas of $R b 1^{\text {lox/- }}$ Chx10-cre mice (Fig. 41-o) but the inner plexiform layer was intact (Fig. $4 \mathbf{p}-\mathbf{s})$.
Figure 2 Proliferation of retinal

progenitor cells is altered in retinas of $R b 1^{-1-}$ mice. (a) The retinas with lens

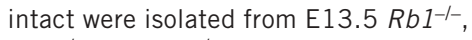
$R b 1^{+/-}$and $R b 1^{+/+}$embryos and rapidly transferred to explant culture. (b) After $12 \mathrm{~d}$ in culture, dissected retinas from E13.5 Rb-deficient embryos (top panel) contained substantially more cells than did retinas from wild-type littermates (bottom panel; $1.61 \pm 0.25 \times 10^{6}$ versus $2.86 \pm 0.37 \times 10^{6}$ cells, respectively). (c,d) After BrdU pulse labeling for $1 \mathrm{~h}$ at E13.5, we found comparable proportions and distributions of $\mathrm{BrdU}^{+}$cells (red) in the nuclei (green) of $\mathrm{RbI}^{-/-}, \mathrm{RbI}^{+/-}$and $R b 1^{+/+}$retinal progenitor cells. (e,f) The fraction of cells in $\mathrm{S}$ phase was greater in $R b 1^{-1-}$ retinal explants after $6 \mathrm{~d}$ in culture but the proportion of cells in G2 was not altered as measured by FACS analysis. (g,h) TUNEL-positive (red) nuclei (green) were widespread in the lens of Rb-deficient mice at E13.5 (arrows). (i) At P6 in vivo, there was apoptotic trimming of excess neurons in the inner nuclear layer of the retina. $(\mathbf{j}, \mathbf{k})$ At a similar stage in the explant cultures (E13.5 + $12 \mathrm{DIC})$, there were also a few apoptotic nuclei (arrow). The proportion and distribution of apoptotic nuclei in $R b 1^{-/-}, R b 1^{+/-}$and $R b 1^{+/+}$ retinas were the same at all stages examined. ONBL, outer neuroblastic layer; INBL, inner neuroblastic layer; $\mathrm{ONL}$, outer nuclear layer; INL, inner nuclear layer; OPL, outer plexiform layer. Scale bars: b, 1 mm; c,d,j,k, $25 \mu \mathrm{m} ; \mathbf{i}$, $10 \mu \mathrm{m}$. a
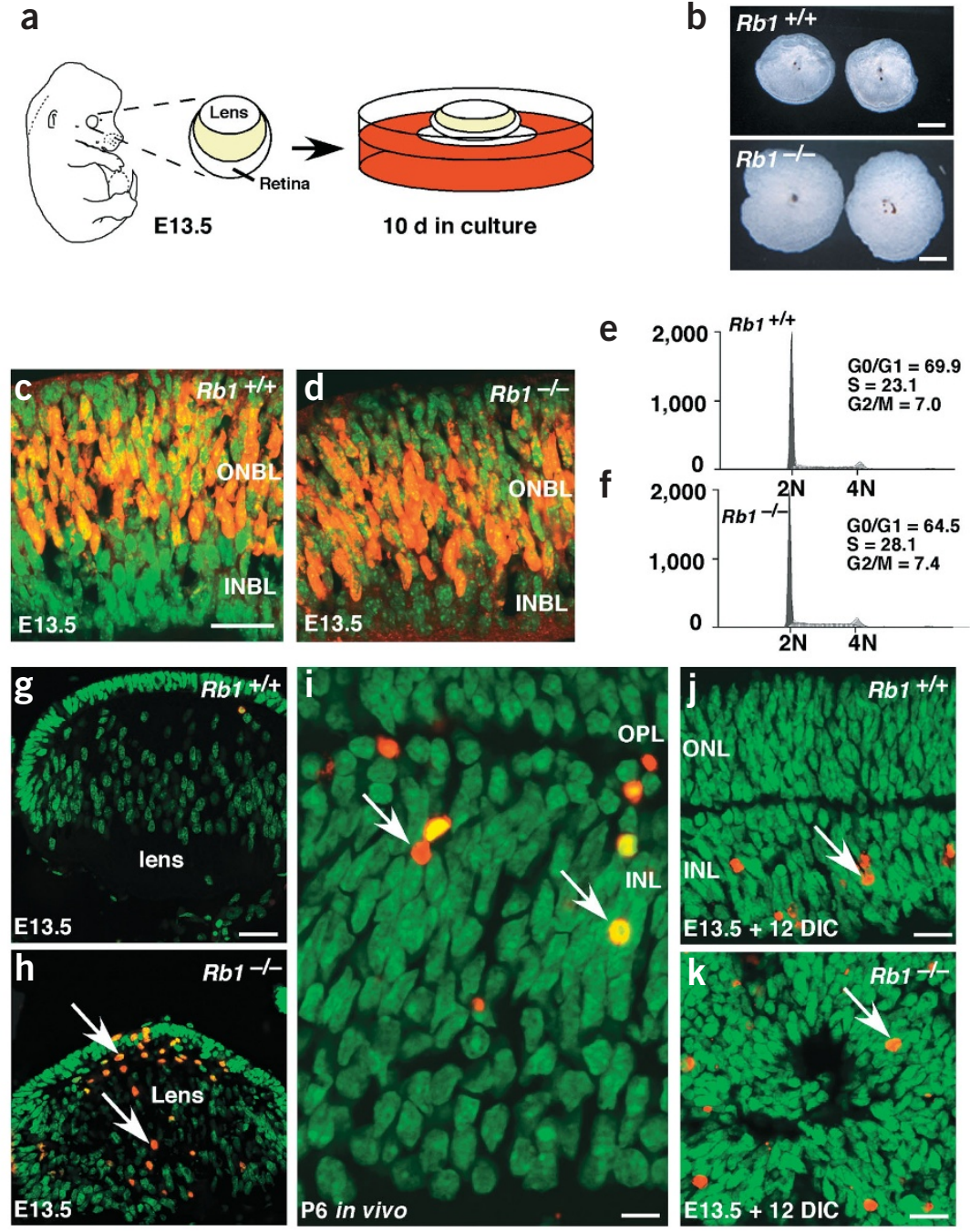


\section{Cell-autonomous role of $\mathbf{R b}$}

Many of the phenotypes associated with the inactivation of $\mathrm{Rb}$ in the developing mouse embryo are non-cell autonomous ${ }^{18}$. For example, in $R b 1$-deficient embryos with wild-type placentas $^{23}$, several of the hematopoietic and CNS defects initially identified in the Rb1-knockout mice were rescued by restoration of the $R b 1$ gene in the placenta. To test whether the proliferation and rod development defects in our $R b 1$-null explant cultures were cell autonomous or non-cell autonomous, we generated a series of replication-incompetent retroviruses carrying the oncogene E1A (Fig. 5a). E1A binds and inactivates all Rb family members ${ }^{24}$. We infected retinal explants of E14.5 embryos with the NIN-E ${ }^{\mathrm{E} 1 \mathrm{~A}}$ retrovirus and maintained them in culture for $10 \mathrm{~d}$. Each clone of cells originating from an individual infected retinal progenitor cell was surrounded by thousands of uninfected cells (Fig. $5 \mathbf{b}$ ). By analyzing the size of clones infected with NIN-E ${ }^{\mathrm{E} 1 \mathrm{~A}}$ compared with those infected with NIN-E, we ascertained whether $\mathrm{Rb}$ inactivation led to deregulated proliferation in a cell-autonomous manner. Clones infected with NIN-E $\mathrm{E}^{\mathrm{E} 1 \mathrm{~A}}$ were significantly larger than those infected with NIN-E (Fig. 5c-f). For example, the proportion of one-cell clones was $44 \%$ for NIN-E and $19 \%$ for NIN-E ${ }^{\text {E1A }}$
$(P<0.001)$. There was also a compensatory increase in large clones for NIN-E ${ }^{\text {E1A }}(>5$ cells $)$ at $48 \%$ as compared with NIN-E at $4 \%(P<0.001)$.

To test whether the role of $\mathrm{Rb}$ in rod development was also cell autonomous, we infected retinas from $\mathrm{P} 0$ rats in vivo with LIA-E $\mathrm{E}^{\mathrm{E} 1 \mathrm{~A}}$; $\mathrm{P} 0$ is the peak period of rod genesis in rats ${ }^{25}$. We infected the contralateral eye with LIA-E as an internal control. After 3 weeks, we stained the retinas for alkaline phosphatase expression (Fig. 5g,h) and reconstructed clones derived from individual infected retinal progenitor cells from serial sections. None of the rod-containing clones ( 0 of 61 ) differentiated normally when E1A was ectopically expressed (Fig. 5i-k and Supplementary Table 2 online). Neither the inner nor outer segments formed normally, and the rod pedicles were disrupted (compare Fig. 5i with Fig. 5j). Many of the inner nuclear layer clones were extremely large and spanned as much as $20 \%$ of the retinal surface area (Fig. $\mathbf{5 h}, \mathbf{k}$ ). This finding is consistent with the proliferation defect characterized in the NIN-E $\mathrm{E}^{\mathrm{E} 1 \mathrm{~A}}$ experiment.

E1A binds and inactivates other proteins, along with the Rb family, that regulate proliferation, such as $\mathrm{p} 300$ (also called CBP $)^{24}$. We generated a series of mutant forms of E1A to determine if the proliferation
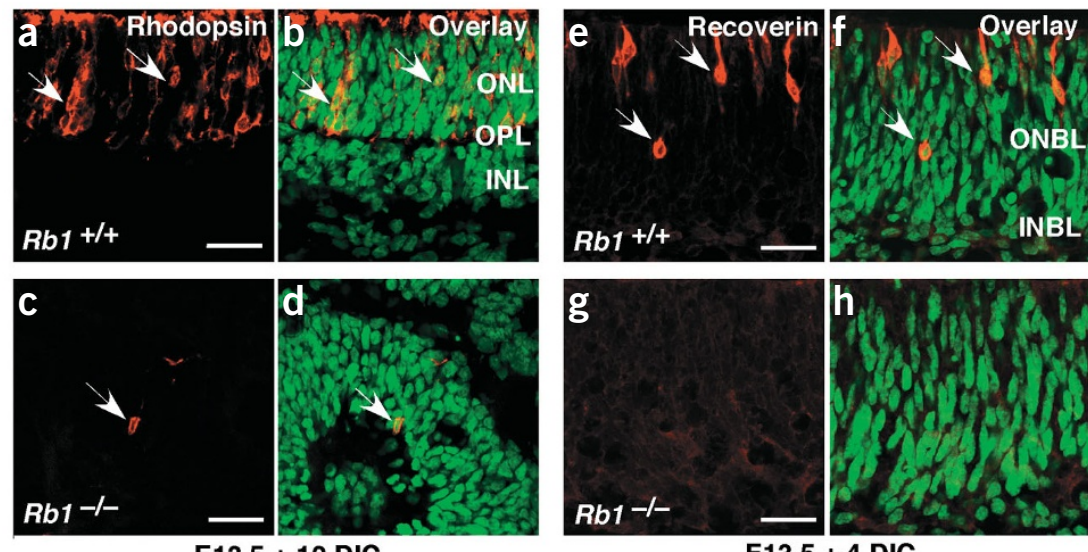

E13.5 + 12 DIC
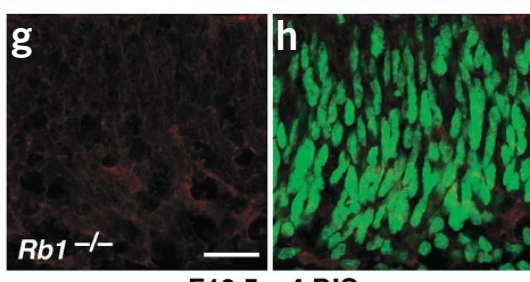

E13.5 + 4 DIC
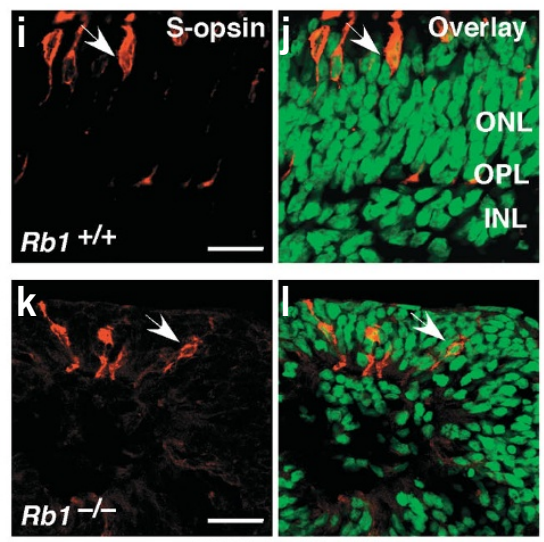

$\mathrm{E} 13.5+12$ DIC
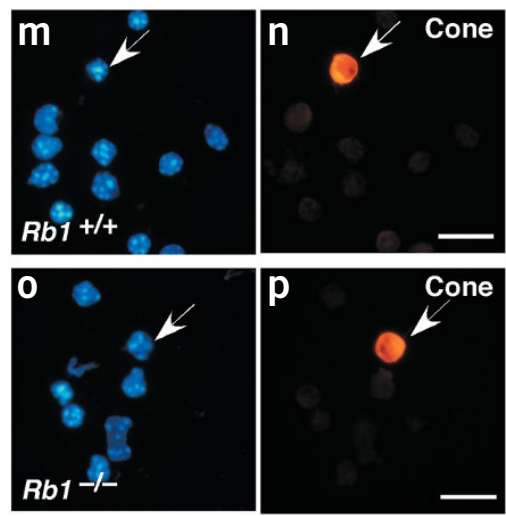
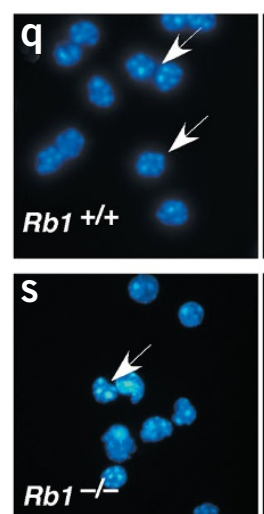
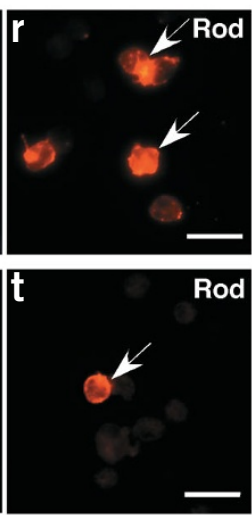

u

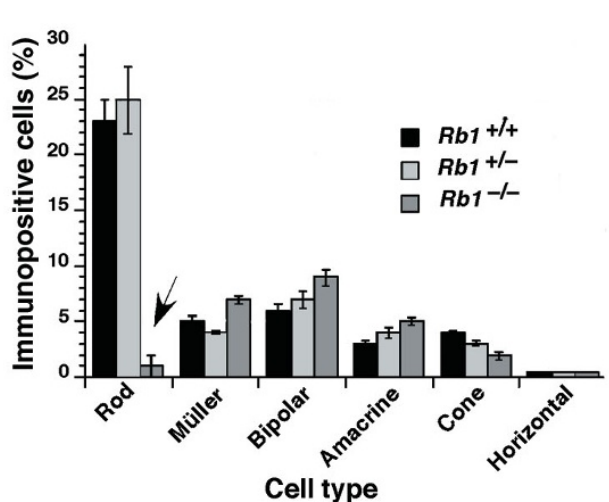

Figure $3 \mathrm{RbI}^{-1-}$ retinas contain fewer rods. Retinal explant cultures were immunolabeled with antibodies to 36 different markers of retinal cell types and structures. (a-d) $R b 1^{-1-}$ retinas lack rhodopsin-immunopositive rod photoreceptors (red) after 12 d in culture. Only one rhodopsin-immunopositive cell was identified in 12 sections from six different Rb deficient retinal explants. (e-h) Abundance of an earlier marker of photoreceptor development, recoverin (red), was also reduced in Rb-deficient retinal explants. (i-I) Unlike the retinas of $\mathrm{Nr}$-deficient embryos, those of $R b 1^{-/-}$and $R b 1^{+/+}$embryos have a similar number of S-cone cells (arrow). Retinal explants were dissociated and immunolabeled with antibodies that recognize different retinal cell types. ( $\mathbf{m}-\mathbf{p}$ ) The proportion of cone arrestin-immunopositive cells was similar in $R b 1^{-/-}, R b 1^{+/-}$and $R b 1^{+/+}$retinal explants. (q-t) The number of rhodopsin-immunopositive cells was markedly lower in the retinas of Rb-deficient embryos. (u) A total of 500-1,000 cells were scored in each of five retinas from $R b 1^{-/-}, R b 1^{+/-}$and $R b 1^{+/+}$ embryos. The number of rhodopsin-immunopositive cells was more than 25 times lower in the retinas of $R b 1$-null embryos (arrow). Most other cell types were only modestly affected by the loss of Rb. Data presented are from rhodopsin (rod), glutamine synthetase (Müller glia), PKC $\alpha$ (bipolar), Pax6 (amacrine), cone arrestin (cone) and calbindin (horizontal cells). ONBL, outer neuroblastic layer; INBL, inner neuroblastic layer; ONL, outer nuclear layer; INL, inner nuclear layer; OPL, outer plexiform layer. Scale bars: a-I, $25 \mu \mathrm{m} ; \mathbf{m}-\mathbf{t}, 10 \mu \mathrm{m}$. 
and rod differentiation effects were due to inactivation of the $\mathrm{Rb}$ family, p300 or other E1A-interacting proteins (Supplementary Fig. 3 online). One mutant form of E1A ( $\Delta 121-127)$ could no longer bind the Rb family ${ }^{24}$; another $(\Delta 4-25)$ could no longer bind p300; and a third mutant lacked the ability to bind to either family of proteins (Supplementary Fig. 3 online). We cloned cDNAs encoding all three forms into LIA-E and NIN-E and used them to infect P0 retinal progenitor cells in vivo or E14.5 retinal progenitor cells in explant culture, respectively. Ectopic expression of the mutant form of E1A that lacked the $\mathrm{Rb}$ binding domain $(\Delta \mathrm{Rb})$ resulted in smaller clones relative to those generated by normal E1A expression (Supplementary Fig. 3 online) and completely rescued the rod defect induced by E1A (Supplementary Fig. 4 and Supplementary Table 2 online). Although $\mathrm{Rb}$ family binding and inactivation accounted for a substantial amount of ectopic proliferation in retinal progenitor cells (compare NIN-E ${ }^{\mathrm{E} 1 \mathrm{~A}}$ with NIN-E ${ }^{\mathrm{E} 1 \mathrm{~A} \Delta \mathrm{Rb}}$; Supplementary Fig. 3 online), deletion of the p300 domain was also required to reduce clone size to normal levels.

All Rb family members (Rb, p107 and p130) were inactivated in retinal cells infected with LIA-E $\mathrm{E}^{\mathrm{E} 1 \mathrm{~A}}$ or NIN-E $\mathrm{E}^{\mathrm{E} 1 \mathrm{~A}}$. To specifically inactivate $\mathrm{Rb}$, we infected retinas of $R b 1^{\text {lox/lox }}$ or $R b 1^{\text {lox/- }}$ mice with replication- incompetent retroviruses carrying Cre recombinase (Fig. 5a). Cre expressed from these viruses mediates efficient recombination at lox $\mathrm{P}$ sites in retinal progenitor cells in vitro and in vivo ${ }^{2}$. Retinas from $R b 1^{\text {lox/lox }}$ newborn mice were infected in vivo with LIA ${ }^{\text {Cre }}$, and E14.5 retinal explants were infected with NINCre. Clones of cells in $R b 1^{\text {lox/lox }}$ retinas infected with $\mathrm{NIN}^{\mathrm{Cre}}$ were significantly larger than clones derived from $R b 1^{\text {lox/lox }}$ retinas infected with NIN (Fig. 5f) or $R b 1^{\text {lox/+ }}$ retinas infected with $\mathrm{NIN}^{\mathrm{Cre}}$ (data not shown). For example, the percentage of small clones was reduced from $44 \%$ for NIN to $23 \%$ for $\mathrm{NIN}^{\mathrm{Cre}}(P<0.01)$. Similarly, the percentage of large clones was increased from $4 \%$ for NIN to $25 \%$ for $\mathrm{NIN}^{\mathrm{Cre}}(P<0.001)$. The average clone size for NIN was $2.19 \pm 1.69$ and for NIN ${ }^{\text {Cre }}$ was $11.5 \pm 8.7$.

To test the cell-autonomous role of $\mathrm{Rb}$ in rod development, we injected LIA $^{\text {Cre }}$ (Fig. 5a) into the left eyes and control virus (LIA) into the right eyes of newborn $R b 1^{\text {lox/lox }}$ mice. Rods did not develop normally when $R b 1$ was inactivated in individual retinal progenitor cells (Fig. 5l,m).

\section{DISCUSSION}

$\mathrm{Rb}$ is expressed in proliferating retinal progenitor cells in the postnatal mouse retina and in differentiating rod photoreceptors. In these
Figure 4 Conditional inactivation of $\mathrm{Rb}$ in retinal progenitor cells. (a) Our BACChx 10 transgenic line was crossed to $\mathrm{RbI}^{+/-}$mice to generate $\mathrm{Ch} \times 10$-cre $\mathrm{RbI}^{+/-}$ mice, which were then crossed to $R b 1^{\text {lox/lox }}$ mice to generate $\mathrm{Ch} \times 10$-cre $R b 1^{\text {lox/- }}$ offspring. After 2 weeks, the retinal phenotype in these mice recapitulated the phenotype characterized in retinal explant cultures. (a-d) Recoverin (red fluorescence) was expressed in all photoreceptors (green fluorescent nuclei) in retinas of $\mathrm{Chx} 10$-cre $R b 1^{\mathrm{lox} /+}$ mice, whereas there was only patchy expression in those of Chx10-cre Rb1 $1^{\text {lox/- }}$ mice. $(\mathbf{e}-\mathbf{g})$ A similar pattern was observed for rhodopsin expression. The nuclei of rhodopsin-immunopositive cells had a similar heterochromatin pattern to that seen for normal rods (arrow), whereas the nuclei of rhodopsin-negative cells in the outer nuclear layer did not have the same heterochromatin pattern (open arrowhead). (h-k) Cones were present in the appropriate proportion and position in the retinas of Chx1O-cre Rb1 $1^{\text {loxl-mice but }}$ were somewhat disorganized due to the lack of rods. (I-s) A similar pattern was seen for all other markers, including calbindin-immunopositive horizontal cells and dopaminergic amacrine cells. ONBL, outer neuroblastic layer; INBL, inner neuroblastic layer; ONL, outer nuclear layer; INL, inner nuclear layer; OPL, outer plexiform layer. Scale bars: $\mathbf{a}-\mathbf{g}, 10 \mu \mathrm{m}$; h-s, $25 \mu \mathrm{m}$.
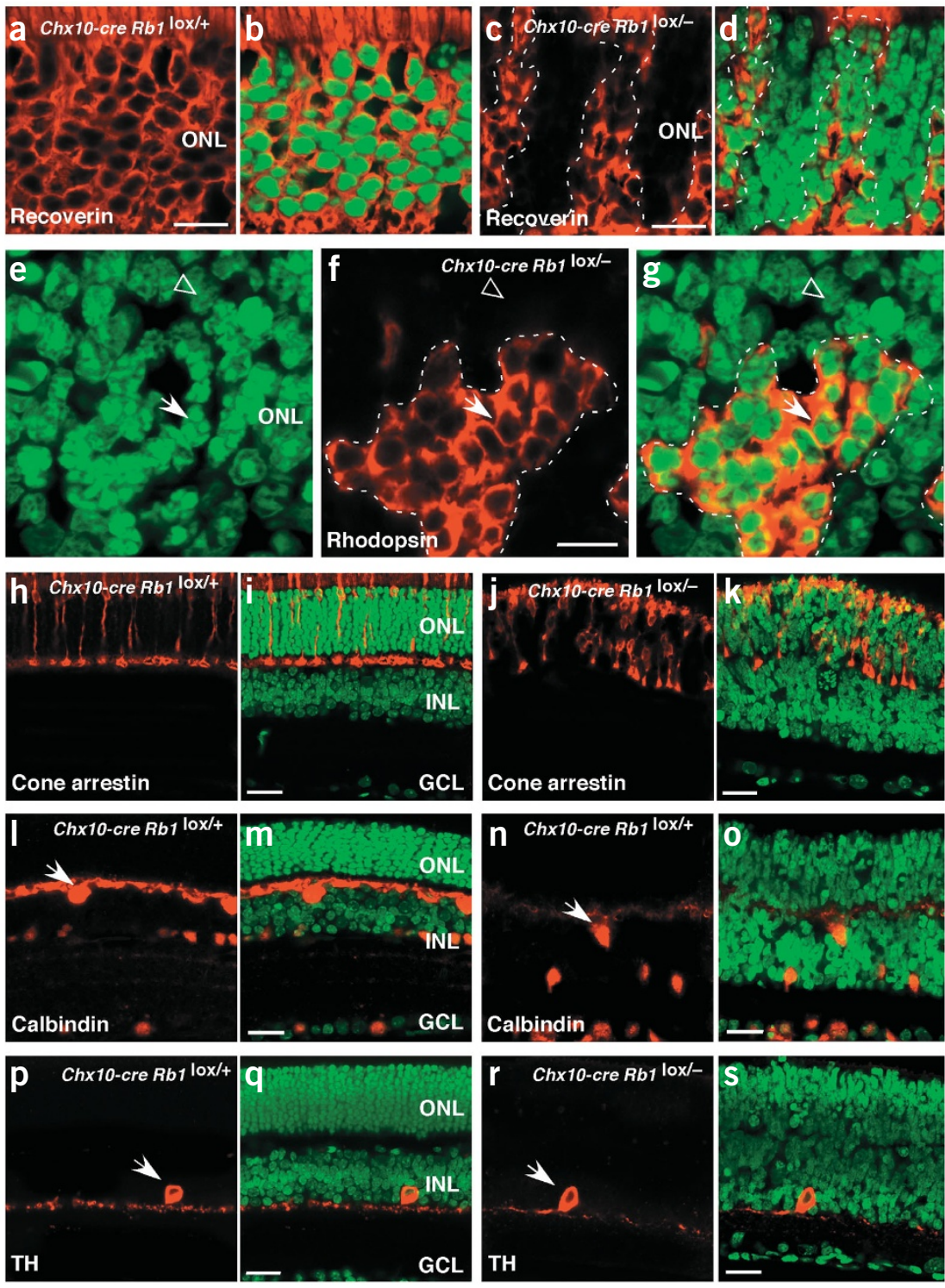
two cell populations, $\mathrm{Rb}$ has two different roles: in dividing retinal progenitor cells, $\mathrm{Rb}$ is required for efficient cell cycle exit; in differentiating rods, it is required for appropriate maturation. Rb has distinct roles in the regulation of retinal progenitor cell proliferation and in the development of rod photoreceptors; namely, the changes in retinal progenitor cell proliferation do not account for the rod defect. In contrast to the role of $\mathrm{Rb}$ in other regions of the developing CNS, its dual role in these two retinal cell populations is cell autonomous.

The colocalization of $\mathrm{H}^{3}$-thymidine and $\mathrm{Rb}$ combined with the localization of $\mathrm{Rb}$ to the inner neuroblastic layer of the postnatal retina indicates that $\mathrm{Rb}$ is expressed in proliferating retinal progenitor cells. BrdU labeling and total cell counts showed that retinal progenitor cells continue to divide in the absence of $\mathrm{Rb}$. Unlike other regions of the CNS, retinal explants that lack $R b 1$ show no apoptosis or G2 arrest. At E13.5, proliferation and apoptosis were indistinguishable among retinas of $R b 1^{-/-}, \mathrm{Rb}^{+/-}$and $R b 1^{+/+}$embryos. This finding is consistent with the low levels of Rb expression at this stage (J.Z. and M.A.D., unpublished results). In contrast, the lens in E13.5 $R b 1^{-1-}$ embryos had ectopic S-phase entry and apoptosis (Fig. 2), which suggests that the development of the lens is strictly dependent on $\mathrm{Rb}$ at E13.5. For example, p107 may serve a compensatory or redundant role at E13.5 in the retina but not in the lens. When proliferation was disrupted at a later stage (E13.5 + 6 DIC), deregulation was not complete; therefore, other $\mathrm{Rb}$ family members may have redundant or compensatory roles during later stages of development in the retina. Indeed, the microarray data are consistent with p107 upregulation in $\mathrm{Rb}$-deficient retinas. Findings from previous genetic studies are consistent with this conclusion ${ }^{26-28}$. Nonetheless, compensation or redundancy by other $\mathrm{Rb}$ family members is not sufficient to rescue completely the proliferation defect resulting from the loss of $R b 1$;

a

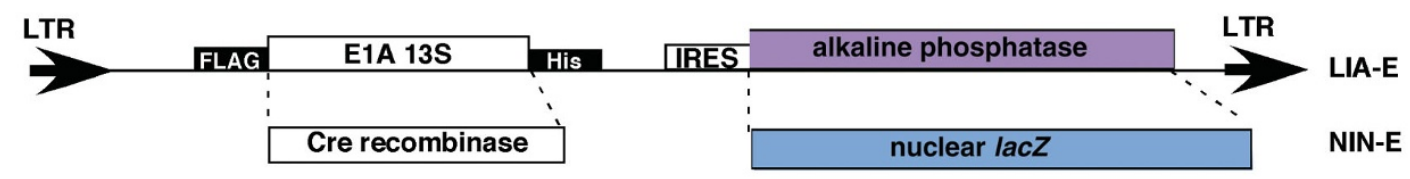

b
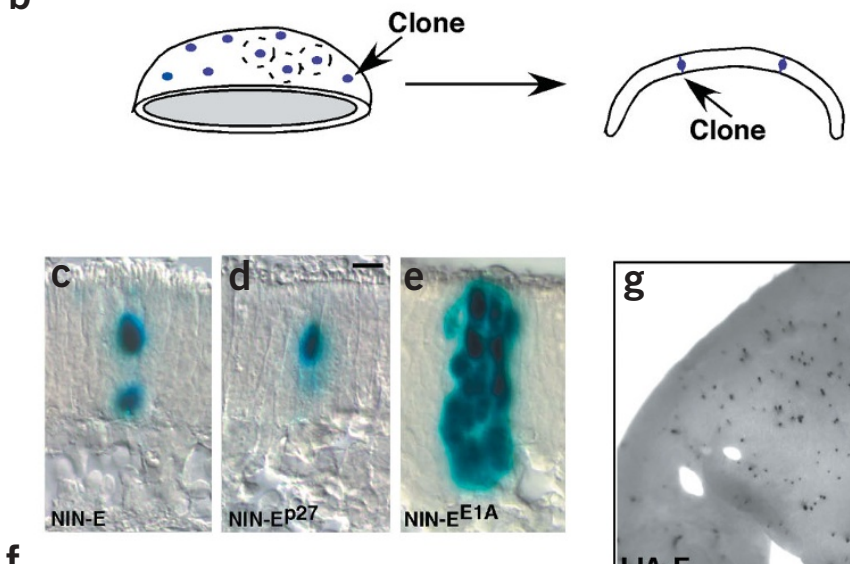

f
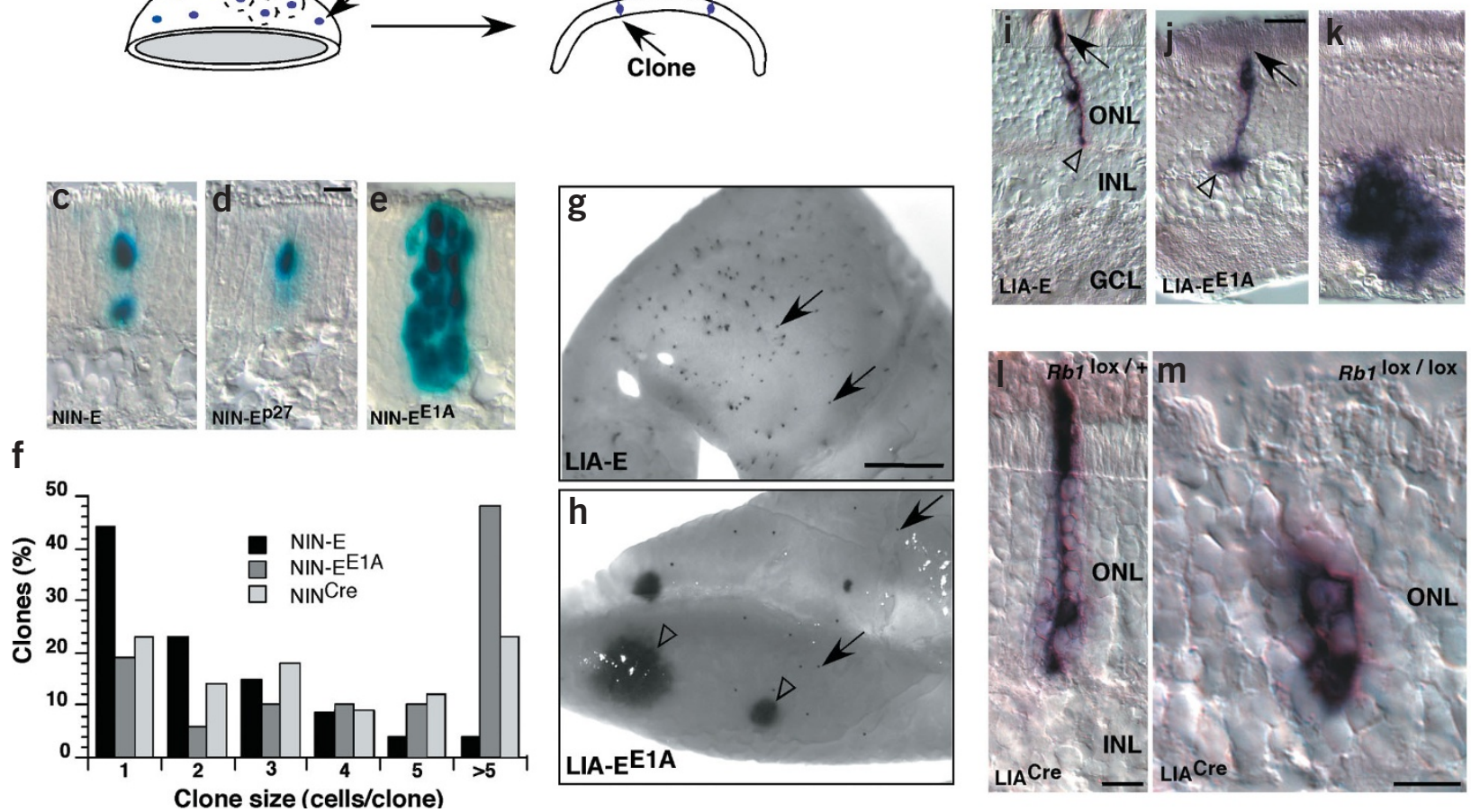

Figure 5 Clonal inactivation of $\mathrm{Rb}$ and the Rb family in retinal progenitor cells in vivo. (a) To determine whether Rb was required in a cell-autonomous manner for the proper regulation of retinal progenitor cell proliferation and rod development, we cloned the oncogene E1A into two replication-incompetent retroviruses. E1A binds and inactivates the entire Rb family. The Cre recombinase was also cloned into these retroviral vectors to inactivate $R b 1$ in clones of cells derived from infected retinal progenitor cells of $R b 1^{\text {lox/lox }}$ or $R b 1^{\text {lox/- }}$ mice. (b) Infected retinas contained clones of cells (circles) that were separated by more than 10,000 uninfected cell (dashed rings). The space between clones suggests that each develops in an otherwise wild-type environment.

(c-f) E14.5 retinal explants were infected with NIN-E or NIN-EE1A and cultured for $10 \mathrm{~d}$. Clones were larger when the Rb family was inactivated by ectopic E1A expression. A previously characterized virus encoding the cyclin kinase inhibitor p27 was used as a control. Similar experiments were carried out with the NINCre virus except the infections were done on $R b l^{\text {lox } / \text { lox }}$ retinas. More than 600 clones were scored and used to compile the summary histogram. $(\mathbf{g}, \mathbf{h})$ Whole rat retinas 3 weeks after injection of LIA-E or LIA-EE1A at PO were stained for alkaline phosphatase expression. Dark spots represent individual clones derived from single retinal progenitor cells (arrows). E1A expression led to exceptionally large clones (open arrowheads), as well as some typical smaller clones (arrows). (i-k) Clones derived from retinal progenitor cells infected with LIA-E contained rods and various inner nuclear layer cells (data not shown). When the entire $\mathrm{Rb}$ family was inactivated by ectopic E1A expression, rods did not mature properly. (I,m) In retinal progenitor cells from $R b 1^{10 x / l o x}$ mice, the conditional inactivation of Rb mediated by LIACre led to a similar disruption in rod development. IRES, internal ribosome entry site; ONL, outer nuclear layer; INL, inner nuclear layer; GCL, ganglion cell layer. Scale bars: c-e,i-m, 25 m; g,h, 1 mm. 
thus, Rb family members may not be completely interchangeable in the developing retina in vivo.

$\mathrm{Rb}$ is localized to the differentiating photoreceptors as well as other neuronal and glial cell types in the adult retina. It is notable that the subcellular pattern of expression of $\mathrm{Rb}$ in the photoreceptors is distinct from that in other neurons and in the retinal progenitor cells. $\mathrm{Rb}$ appears to circumscribe heterochromatin in the photoreceptors ${ }^{14}$, whereas it appears in a diffuse nuclear pattern in neurons and progenitor cells. It has been suggested that the genome is divided into transcriptional domains and that this organization is regulated by a higher order chromatin structure that is organized by histones ${ }^{29-32}$. Rb is recruited to specific promoters through protein-protein interactions with E2F/DP heterodimers bound to their cognate binding sites ${ }^{33}$. Rb recruits histone deacetylase to a subset of these promoters, and as a consequence, chromatin organization may be altered at certain domains in the genome ${ }^{34}$. Rod photoreceptors have a form of chromatin organization that is distinct from that of other neurons and glia in the retina (see Fig. 4c for an example). Thus, appropriate rod maturation may require chromatin reorganization mediated by $\mathrm{Rb}$. Alternatively, $\mathrm{Rb}$ may regulate photoreceptor-specific gene expression through interactions with other transcription factors ${ }^{11}$. It is not known at this time which of the genes that have altered expression in $\mathrm{Rb} 1$-deficient retinas are direct targets of $\mathrm{Rb}$.

In many experimental systems, it can be challenging to separate effects on cell fate specification or differentiation from those on proliferation. Changes in proliferation often affect developmental decisions and vice versa ${ }^{1,2}$. In the Rb-deficient retinas, our data suggest that the effect on proliferation is separate from the effect on rod development. If the absence of rods in $R b 1$-null retinas was due to an alteration in cell proliferation, then a similar effect should have been detected in other cell types generated at the same time during development (bipolar cells and Müller glia). But the ratios of these cell types in retinas of $R b 1^{-/-}, R b 1^{+/-}$and $R b 1^{+/+}$embryos were similar. Moreover, ectopic rounds of cell division during the postnatal period when rods are normally generated should have resulted in an increase in the number of rod photoreceptors, and not a decrease, as seen in the $R b 1$-null retinas. It is possible that there is a delay in rod development in the absence of $\mathrm{Rb}$, and long-term studies of photoreceptor differentiation in $\mathrm{Rb} 1$-null retina is ongoing.

$\mathrm{Nrl}$ is an essential component of the rod development program ${ }^{35}$. In the absence of $\mathrm{Nrl}$, rods are replaced by $\mathrm{S}$ cones. This finding led to a model in which newly postmitotic cells commit to the photoreceptor fate, and $\mathrm{Nrl}$ is then required for rod development. In the absence of $\mathrm{Nrl}$, cells that would have become rods are believed to adopt a default $\mathrm{S}$-cone fate $\mathrm{e}^{35}$. In the absence of $\mathrm{Rb}$, rods do not form, but there is no compensatory increase in numbers of $S$ cones or other cell types. The genes whose expression is increased in $\mathrm{Rb}^{-/-}$retinas are cell cycle or progenitor cell genes. Thus, we believe the cells that would have become rods are immature cells with gene expression profiles similar to retinal progenitor cells. The morphological disruption (see Fig. 2k) observed in Rb1-null retinas is probably due to the failure of rods to form during development.

$\mathrm{Nrl}$ is downregulated by a factor of 9 in $R b 1^{-/-}$retinas. This result may indicate that $\mathrm{Rb}$ acts upstream of $\mathrm{Nrl}$. Consistent with this hypothesis, $\mathrm{Nr} 2 \mathrm{e} 3$, a gene that is believed to be downstream of $\mathrm{Nrl}^{35}$, is also downregulated (by a factor of 22) in the absence of $\mathrm{Rb}$. The immunolabeling and microarray data are consistent with this hypothesis. The microarray data not only verify that rods depend on $\mathrm{Rb}$ for development, but also highlight the defect in the rod development pathway, which should help identify $\mathrm{Rb}$-dependent target genes. It will be of particular interest to determine if these targets are regulated by chromatin reorganization mediated by histone deacetylase or interaction with other retina-specific transcription factors.

In some tissues that normally rely on $\mathrm{Rb}$ to regulate cell cycle exit and subsequent steps during development, compensation by related family members can occur when $\mathrm{Rb}$ is absent. For example, in normal proliferating myocytes, $\mathrm{Rb}$ is expressed and $\mathrm{p} 107$ is absent ${ }^{36}$. When $\mathrm{Rb}$ is eliminated, p107 is upregulated in a compensatory manner ${ }^{36}$. Although p107 efficiently compensates for $\mathrm{Rb}$ in proliferating

Table 1 Representative downregulated genes in retinal explants of $R b 1^{-/-}$mice from microarray hybridization

\begin{tabular}{|c|c|c|c|c|}
\hline Gene $^{a}$ & Accession number & Cell type or structure & Relative change $^{b}$ & $t$-test or ANOVA \\
\hline Rhodopsin & BE950266 & Rod & 100 & 0.0003 \\
\hline Rod channel & P29974 & Rod & 100 & 0.005 \\
\hline 7-dehydrocholesterol reductase & BE986568 & Smith-Lemli-Opitz syndrome, developmental defects & 100 & 0.01 \\
\hline Guanylate cyclase activator $1 \mathrm{a}$ & BE954739 & Photoreceptors & 90 & 0.001 \\
\hline Phosphodiesterase cGMP & BE954784 & Rod & 58 & 0.01 \\
\hline Phosphodiesterase 6G cGMP-specific rod & BE950361 & Rod & 58 & 0.01 \\
\hline Peripherin 2 & BE983428 & Rod & 55 & 0.00006 \\
\hline Transcription factor EB & BF460609 & BHLH-Zip, unknown function or localization & 52 & 0.0001 \\
\hline Retinitis pigmentosa 1 & BF466742 & Rod & 40 & 0.03 \\
\hline Nuclear receptor subfamily 2 , group E, member 3 & BE952231 & Rod & 22 & 0.01 \\
\hline Rod outer segment membrane protein 1 & BE950239 & Rod & 19 & 0.0004 \\
\hline Recoverin & BE950233 & Photoreceptors, bipolar subset & 17 & 0.008 \\
\hline Blue cone opsin & B54679 & S cones & 17 & 0.017 \\
\hline S-antigen & BE950531 & Rod arrestin & 13 & 0.008 \\
\hline Rod photoreceptor 1 & BE950711 & Rod & 11 & 0.0008 \\
\hline Neural retina leucine zipper & BF464350 & Rod & 9 & 0.029 \\
\hline Insulin-like growth factor binding protein 5 protease & BF463798 & Localization unknown & 7 & 0.0007 \\
\hline X-box binding protein 1 & BE988192 & Plasma cell differentiation, unfolded protein response & 7 & 0.03 \\
\hline Guanine nucleotide binding protein beta 1 & BF463798 & Rod & 7 & 0.038 \\
\hline Rod cyclic nucleotide gated channel & Q9JJZ8 & Rod & 6 & 0.049 \\
\hline
\end{tabular}

${ }^{a}$ A subset of the genes with significant differences are shown here, duplicates spots with the same genes are not shown. Duplicate spots with the same genes are not shown, nor are unknown expressed-sequence tags. The complete data set is available in the GEO database. bSix independent wild-type and knockout samples were compared from three different litters. A representative pair is shown here. Complete data can be found in the GEO database. 
Table 2 Representative upregulated genes in retinal explants of $R b 1^{-/-}$mice from microarray hybridization

\begin{tabular}{|c|c|c|c|c|}
\hline Gene $^{a}$ & Accession number & Function & Relative change $^{\mathrm{b}}$ & $t$-test or ANOVA \\
\hline Cyclin-dependent kinase inhibitor $1 \mathrm{a}$ & Al326605 & Cell cycle and proliferation & 12 & 0.002 \\
\hline Topoisomerase II alpha & BF467500 & DNA replication and proliferation & 10.9 & 0.00018 \\
\hline Mini chromosome maintenance 6 & BE951546 & Helicase and DNA replication & 10.6 & 0.028 \\
\hline $\mathrm{CDC} 2 \mathrm{~A}$ & AW210382 & Cell cycle G1-S, proliferation & 10.1 & 0.016 \\
\hline Mini chromosome maintenance 5 & BE953148 & Helicase and DNA replication & 8.4 & 0.046 \\
\hline Cyclin $B 1$ related 1 & BE988710 & Cell cycle G2-M, proliferation & 7.6 & 0.0002 \\
\hline Cyclin A2 & BF466271 & Cell cycle and proliferation & 6.6 & 0.00003 \\
\hline Replication protein $\mathrm{A} 2$ & BF463264 & DNA replication and proliferation & 6.3 & 0.001 \\
\hline DNA ligase I & BE988961 & DNA replication and repair, proliferation & 6.0 & 0.003 \\
\hline Cyclin E & BF462594 & Cell cycle G1-S, proliferation & 5.8 & 0.01 \\
\hline Ribonuclease reductase $\mathrm{M} 2$ & BE984641 & DNA replication and proliferation & 5.8 & 0.05 \\
\hline Cyclin-dependent kinase inhibitor $1 \mathrm{c}$ & AA671166 & Cell cycle and proliferation & 4.9 & 0.04 \\
\hline Rac GTP-ase-activating 1 & BF464176 & NA & 4.8 & 0.017 \\
\hline CDC25C & AA623344 & Activates CDC2, proliferation & 4.6 & 0.001 \\
\hline Cyclin F & AI326604 & Cell cycle S-G2, proliferation & 4.5 & 0.019 \\
\hline Mini chromosome maintenance 2 & BF461400 & Helicase and DNA replication & 4.4 & 0.036 \\
\hline Cyclin A2 & AA469716 & Cell cycle and proliferation & 4.4 & 0.018 \\
\hline Centromere antigen $\mathrm{A}$ & BF465621 & Nucleosomes and centromeres, DNA replication & 4.0 & 0.001 \\
\hline Cystein rich protein 2 & BE982889 & Dedifferentiation and proliferation & 4.0 & 0.024 \\
\hline DEAD box 3 & BE949690 & Putative RNA helicase & 4.0 & 0.0001 \\
\hline Retinoblastoma-like 1 & AA738977 & Cell cycle and proliferation & 4.0 & 0.029 \\
\hline
\end{tabular}

${ }^{a} A$ representative set of 22 genes arranged in order of relative upregulation are presented. Duplicate spots with the same genes are not shown, nor are unknown expressed-sequence tags. The complete data set is available in the GEO database. ${ }^{b} \mathrm{Six}$ independent wild-type and knockout samples were compared from three different litters. A representative pair is shown here. Complete data can be found in the GEO database.

myocytes, it was ineffective at keeping newly postmitotic cells from reentering the cell cycle. Therefore, p107 could only partially compensate for $\mathrm{Rb}$ in developing muscle. p107 is not expressed in the postnatal mouse retina (J.Z. and M.A.D, unpublished data). Our microarray data indicate that p107 is upregulated in Rb1-deficient retinal progenitor cells (Table 2). Upregulation by p107 provides partial functional compensation for deregulated proliferation in retinal progenitor cells, because when the entire $\mathrm{Rb}$ family is inactivated using E1A, massive hyperplasia occurs (Fig. 5h). Despite the partial compensation by 107 to regulate proliferation of retinal progenitor cells, however, it cannot take the place of $\mathrm{Rb}$ in rod development, as rods do not form in the Rb1-deficient retinas despite p107 upregulation. Thus, we believe that p107 can partially compensate for one of the roles (proliferation regulation) of $\mathrm{Rb}$ in retinal development, but not the other (rod development). Notably, $\mathrm{Rb}$ is not the main family member expressed in embryonic retinal progenitor cells. We are currently carrying out experiments to test if $\mathrm{Rb}$ can compensate for $\mathrm{p} 107$ and $\mathrm{p} 130$ in embryonic retinal progenitor cells.

Previous studies using an IRBP-cre mouse line crossed to the $R b 1^{\text {lox/- }}$ mice found that there was no obvious defect in retinal development ${ }^{37}$, although careful analysis of the differentiation of each cell type was not done. IRBP is expressed just as rod photoreceptors exit the cell cycle ${ }^{38}$. Thus, by the time Cre accumulates, recombines the $\mathrm{Rb}$ allele and $\mathrm{Rb}$ protein turns over, the photoreceptors may have initiated the differentiation program. Chx10-cre is expressed in dividing progenitor cells from the earliest stages of development. Cells that would normally go on to become rods in $\mathrm{Rb} 1^{\mathrm{lox} /-} \mathrm{Ch} x 10$-cre retinas have lost the $R b 1$ gene long before they exit the cell cycle. We believe that the discrepancy between the data obtained from retinas of $R b 1^{\text {lox/- }}$ Chxilo-cre

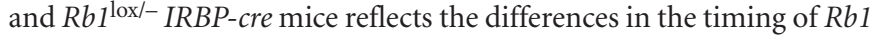
gene inactivation. Consistent with this hypothesis, the microarray data (Tables 1 and 2) suggest that Rb acts very early in rod development. It is conceivable that there is a narrow window during the early stages of rod development when $\mathrm{Rb}$ is required, and if immature rods progress beyond that stage, as in the $R b 1^{\text {lox/- } I R B P-c r e ~ r e t i n a s, ~ r o d s ~ d e v e l o p ~ n o r-~}$ mally. Our retrovirus-mediated inactivation of $R b 1$ is also consistent with a difference in timing of gene inactivation, as the replicationincompetent retroviruses used for these studies can only integrate into the genome of dividing cells.

It is difficult to discern between cell-autonomous and non-cellautonomous roles of proteins in knockout mice because all tissues lack the gene of interest. The generation of conditional knockout mice has enabled researchers to identify non-cell-autonomous effects of gene inactivation, but even this approach can be difficult to interpret, depending on the proportion of cells undergoing recombination. Many of the phenotypes initially identified in the Rb1-knockout embryos were non-cell autonomous ${ }^{18,23}$. To complement our studies on knockout and conditional knockout mice, we carried out clonal analysis using a Cre retrovirus to test the cell-autonomous role of Rb. Each retinal progenitor cell infected with the replication-incompetent retrovirus gave rise to a clone of cells in which $R b 1$ was inactivated by Cremediated homologous recombination. Approximately 10,000 uninfected cells surrounded each clone; therefore, effects on proliferation or development identified in the clones were cell autonomous. Unlike its role in other regions of the mouse CNS, the role of $\mathrm{Rb}$ in the proliferation of the mouse retina and in rod development was cell autonomous.

To further explore the question of cell autonomy, we also used retroviruses expressing E1A., which binds and inactivates all three $\mathrm{Rb}$ family members. Although the rod defect was similar when E1A was expressed or $R b 1$ was inactivated, the large clones in the inner nuclear layer were found only when E1A was expressed. This result may indicate that loss of $\mathrm{Rb}$ alone is not sufficient for the formation of these particularly large clones, and redundancy or compensation by $\mathrm{p} 107$ or p130 may prevent proliferation when Cre is used to inactivate $R b 1$. The earlier genetic studies ${ }^{26-28}$ and our gene expression data (J.G. and M.A.D., unpublished results) are consistent with this hypothesis. A 
better understanding of the complex compensatory and redundant mechanisms of Rb, p107 and p130 in mouse retinal progenitor cells will form a valuable foundation for understanding how mouse retinal progenitor cells are resistant to deregulated proliferation, which in humans ultimately causes retinoblastoma.

\section{METHODS}

Mouse strains. We obtained $R b 1^{+/-}$mice from The Jackson Laboratory and $R b 1^{\text {lox/lox }}$ mice from the National Cancer Institute. All mice were crossed to C57Bl/6 mice purchased from Charles River Laboratories. We purchased timed-pregnant Sprague-Dawley rats from Charles River Labs. The Chx10-cre transgenic mouse line will be described elsewhere (S.R. and C.L.C., unpublished results). The St. Jude Children's Research Hospital Institutional Animal Care and Use Committee approved all of the animal experiments.

Antibodies, immunostaining, BrdU and thymidine. We immunolabeled retinal cryosections and dissociated retinas as previously described ${ }^{39,40}$. The list of antibodies used is provided in Supplementary Table $\mathbf{1}$ online. Antisera to Sopsin and M-opsin were characterized and provided by X.Z. and C.M.C. To label S-phase retinal progenitor cells, we incubated freshly dissected retinas in $1 \mathrm{ml}$ of explant culture medium containing ${ }^{3} \mathrm{H}$-thymidine $\left(5 \mu \mathrm{Ci} \mathrm{m}^{-1} ; 89 \mathrm{Ci}\right.$ $\mathrm{mmol}^{-1}$ ) or $10 \mu \mathrm{M} \mathrm{BrdU}$ for $1 \mathrm{~h}$ at $37^{\circ} \mathrm{C}$. Autoradiography and BrdU detection were carried out as described previously $y^{39,40}$.

FACS and TUNEL analyses. For apoptosis analysis, we sectioned retinas $(14-\mu \mathrm{m})$ on a cryostat. We used the colorimetric TUNEL apoptosis system (Promega) according to the manufacturer's instructions, but we used tyramide-Cy3 (NEN) rather than the colorimetric substrate for detection. For FACS analysis of DNA content, we dissociated retinas as described previously ${ }^{39,40}$, washed them in $1 \times$ phosphate-buffered saline and resuspended them in a solution containing $0.05 \mathrm{mg} \mathrm{ml}^{-1}$ propidium iodide, $0.1 \%$ sodium citrate and $0.1 \%$ Triton X-100. We then treated samples with RNase, filtered them through a $40-\mu \mathrm{m}$ nylon mesh and analyzed them on a FACScan (BecktonDickson). We carried out three independent experiments for a total of 31 embryos. A representative FACS plot is shown in Figure 2.

Microarray hybridization. We obtained a collection of 11,500 retina-specific mouse cDNAs from B. Soares (University of Iowa) and supplemented these with 700 additional clones of genes that regulate the cell cycle, apoptosis and development. Arrays were printed at the Hartwell Center for Bioinformatics \& Biotechnology at St. Jude Children's Research Hospital. We isolated RNA from retinas from each embryo by using Trizol (Invitrogen) and subjected $1 \mu \mathrm{g}$ of total RNA to one round of linear amplification using the RiboAmp System (Arcturus Applied Genomics) to yield $10 \mu \mathrm{g}$ of RNA. We indirectly labeled the RNA using aa-dUTP and conjugated it with Cy3 and Cy5. We then filtered data and carried out cluster analysis using SAM (Significance Analysis of Microarrays) software. We included only data with a $\log _{2}$ relative difference of 2 in Table 1 .

Retroviruses and retinal cultures. Retroviruses and retinal culture procedures are described elsewhere ${ }^{39-41}$. The entire data set for the clonal analysis is presented in table format or histogram for these studies. These data are pooled from 25-50 independent retinas representing at least three independent litters to eliminate any subtle variation in culture conditions or embryo staging. In addition, the control retrovirus was used for the contralateral retina in each experiment. LIA-E encodes alkaline phosphatase, which is suited for in vivo studies of cell fate specification and differentiation, and NIN-E encodes nuclear lac $Z$ and is ideal for analysis of proliferation of retinal progenitor cells.

URLs. The GEO microarray database is available at http://www.ncbi.nlm.nih. gov/geo/. SAM software is available at http://www-stat.stanford.edu/ tibs/SAM/.

GEO accession number. Microarray gene list, procedure and hybridization data and other data with lower relative changes but a q value of zero, RET13K GPL323.

Note: Supplementary information is available on the Nature Genetics website.

ACKNOWLEDGMENTS

We thank L. Dabo for assistance with mouse colonies; D. Naeve and D. Kaushal for retinal microarray printing, hybridization and data analysis; R. Ashmun for assistance with FACS analysis; and A. McArthur for editing the manuscript. This work was supported by grants (to M.A.D.) from the US National Institutes of Health, Cancer Center Support from the US National Cancer Institute and the American Lebanese Syrian Associated Charities. This research was supported in part by Research to Prevent Blindness.

\section{COMPETING INTERESTS STATEMENT}

The authors declare that they have no competing financial interests.

Received 2 December 2003; accepted 29 January 2004

Published online at http://www.nature.com/naturegenetics/

1. Dyer, M.A. \& Cepko, C.L. Regulating proliferation during retinal development. Nat. Rev. Neurosci. 2, 333-342 (2001).

2. Dyer, M.A. Regulation of proliferation, cell fate specification and differentiation by the homeodomain proteins Proxl, Six3, and Chx10 in the developing retina. Cell Cycle 2, 350-357 (2003).

3. DiCiommo, D., Gallie, B.L. \& Bremner, R. Retinoblastoma: the disease, gene and protein provide critical leads to understand cancer. Semin. Cancer Biol. 10, 255-269 (2000).

4. Liu, I.S. et al. Developmental expression of a novel murine homeobox gene (Chx10): evidence for roles in determination of the neuroretina and inner nuclear layer. Neuron 13, 377-393 (1994).

5. Burmeister, M. et al. Ocular retardation mouse caused by Chx10 homeobox null allele: impaired retinal progenitor proliferation and bipolar cell differentiation. Nat. Genet. 12, 376-384 (1996)

6. Nakayama, K. et al. Mice lacking p27(Kip1) display increased body size, multiple organ hyperplasia, retinal dysplasia, and pituitary tumors. Cel/ 85, 707-720 (1996).

7. Dyer, M.A. \& Cepko, C.L. Control of Muller glial cell proliferation and activation following retinal injury. Nat. Neurosci. 3, 873-880 (2000).

8. Ma, C., Papermaster, D. \& Cepko, C.L. A unique pattern of photoreceptor degeneration in cyclin D1 mutant mice. Proc. Natl. Acad. Sci. USA 95, 9938-9943 (1998).

9. Slack, R.S., El-Bizri, H., Wong, J., Belliveau, D.J. \& Miller, F.D. A critical temporal requirement for the retinoblastoma protein family during neuronal determination. $J$. Cell Biol. 140, 1497-1509 (1998).

10. Ferguson, K.L. \& Slack, R.S. The Rb pathway in neurogenesis. Neuroreport 12 A55-A62 (2001)

11. Ferguson, K.L. et al. Telencephalon-specific Rb knockouts reveal enhanced neurogenesis, survival and abnormal cortical development. EMBO J. 21, 3337-3346 (2002).

12. Morris, E.J. \& Dyson, N.J. Retinoblastoma protein partners. Adv. Cancer Res. 82, 1-54 (2001).

13. Alexiades, M.R. \& Cepko, C. Quantitative analysis of proliferation and cell cycle length during development of the rat retina. Dev. Dyn. 205, 293-307 (1996).

14. Cai, S., Han, H.J. \& Kohwi-Shigematsu, T. Tissue-specific nuclear architecture and gene expression regulated by SATB1. Nat. Genet. 34, 42-51 (2003).

15. Jacks, T. et al. Effects of an Rb mutation in the mouse. Nature 359, 295-300 (1992).

16. Lee, E.Y. et al. Mice deficient for $\mathrm{Rb}$ are nonviable and show defects in neurogenesis and haematopoiesis. Nature 359, 288-294 (1992).

17. Clarke, A.R. et al. Requirement for a functional Rb-1 gene in murine development. Nature 359, 328-330 (1992).

18. Lipinski, M.M. et al. Cell-autonomous and non-cell-autonomous functions of the Rb tumor suppressor in developing central nervous system. EMBO J. 20, 3402-3413 (2001)

19. Greenlee, M.H., Wilson, M.C. \& Sakaguchi, D.S. Expression of SNAP-25 during mammalian retinal development: thinking outside the synapse. Semin. Cell Dev. Biol. 13, 99-106 (2002).

20. Dick, O. et al. Localization of the presynaptic cytomatrix protein Piccolo at ribbon and conventional synapses in the rat retina: comparison with Bassoon. J. Comp. Neurol. 439, 224-234 (2001)

21. Koulen, P. Localization of synapse-associated proteins during postnatal development of the rat retina. Eur. J. Neurosci. 11, 2007-2018 (1999).

22. Whitehead, J.L. et al. Photoreceptor localization of the KIF3A and KIF3B subunits of the heterotrimeric microtubule motor kinesin II in vertebrate retina. Exp. Eye Res. 69, 491-503 (1999).

23. Wu, L. et al. Extra-embryonic function of Rb is essential for embryonic development and viability. Nature 421, 942-947 (2003).

24. Frisch, S.M. \& Mymryk, J.S. Adenovirus-5 E1A: paradox and paradigm. Nat. Rev. Mol. Cell Biol. 3, 441-452 (2002).

25. Young, R.W. Cell differentiation in the retina of the mouse. Anat. Rec. 212, 199-205 (1985)

26. Maandag, E.C. et al. Developmental rescue of an embryonic-lethal mutation in the retinoblastoma gene in chimeric mice. EMBO J. 13, 4260-4268 (1994).

27. Williams, B.O. et al. Extensive contribution of Rb-deficient cells to adult chimeric mice with limited histopathological consequences. EMBO J. 13, 4251-4259 (1994).

28. Robanus-Maandag, E. et al. p107 is a suppressor of retinoblastoma development in pRb-deficient mice. Genes Dev. 12, 1599-1609 (1998).

29. Noma, K., Allis, C.D. \& Grewal, S.I. Transitions in distinct histone H3 methylation patterns at the heterochromatin domain boundaries. Science 293, 1150-1155 (2001).

30. Schubeler, D. et al. Nuclear localization and histone acetylation: a pathway for chromatin opening and transcriptional activation of the human beta-globin locus. Genes Dev. 14, 940-950 (2000). 


\section{ARTICLES}

31. Litt, M.D., Simpson, M., Gaszner, M., Allis, C.D. \& Felsenfeld, G. Correlation between histone lysine methylation and developmental changes at the chicken beta-globin locus. Science 293, 2453-2455 (2001).

32. Litt, M.D., Simpson, M., Recillas-Targa, F., Prioleau, M.N. \& Felsenfeld, G. Transitions in histone acetylation reveal boundaries of three separately regulated neighboring loci. EMBO J. 20, 2224-2235 (2001).

33. Dyson, N. The regulation of E2F by pRB-family proteins. Genes Dev. 12, 2245-2262 (1998).

34. Harbour, J.W. \& Dean, D.C. Chromatin remodeling and Rb activity. Curr. Opin. Cell Biol. 12, 685-689 (2000).

35. Mears, A.J. et al. Nrl is required for rod photoreceptor development. Nat. Genet. $\mathbf{2 9}$ 447-452 (2001).

36. Schneider, J.W., Gu, W., Zhu, L., Mahdavi, V. \& Nadal-Ginard, B. Reversal of terminal differentiation mediated by p107 in Rb-/- muscle cells. Science 264, 1467-1471 (1994).
37. Vooijs, M., te Riele, H., van der Valk, M. \& Berns, A. Tumor formation in mice with somatic inactivation of the retinoblastoma gene in interphotoreceptor retinol binding protein-expressing cells. Oncogene 21, 4635-4645 (2002).

38. Liou, G.I. et al. Retina-specific expression from the IRBP promoter in transgenic mice is conferred by 212 bp of the $5^{\prime}$-flanking region. Biochem. Biophys. Res. Commun. 181, 159-165 (1991).

39. Dyer, M.A. \& Cepko, C.L. The p57(Kip2) cyclin kinase inhibitor is expressed by a restricted set of amacrine cells in the rodent retina. J. Comp. Neurol. 429, 601-614 (2001).

40. Dyer, M.A. \& Cepko, C.L. p27Kip1 and p57Kip2 regulate proliferation in distinct retinal progenitor cell populations. J. Neurosci. 21, 4259-4271 (2001).

41. Dyer, M.A., Livesey, F.J., Cepko, C.L. \& Oliver, G. Prox1 function controls progenitor cell proliferation and horizontal cell genesis in the mammalian retina. Nat. Genet. 34 53-58 (2003). 